\title{
PENDAYAGUNAAN MEDIA SOSIAL INSTAGRAM DALAM UPAYA PROMOSI PERPUSTAKAAN PADA DINAS PERPUSTAKAAN DAN KEARSIPAN DAERAH JAWA BARAT
}

\author{
Wibisana Kuspi Ramadhan \\ Prodi Perpustakaan dan Sains Informasi, Fakultas Ilmu Pendidikan, Universitas Pendidikan Indonesia \\ Email: wibisana@upi.edu

\section{Dr. Doddy Rusmono, MLIS.} \\ Prodi Perpustakaan dan Sains Informasi, Fakultas Ilmu Pendidikan, Universitas Pendidikan Indonesia \\ Email: drusmono@upi.edu
}

Received : 01 March 2021

Revised : 05 July 2021

Accepted : 10 September 2021

DOI :

\begin{abstract}
This research contains about the utilization of social media Instagram in an effort to promote the library at the West Java Regional Library and Archives Service. The purpose of this study was to determine the impact of the use of social media Instagram as a media promotion for libraries in the Regional Library and Archives Office of West Java Province. The method used in this research is qualitative with a case study approach, in which the problems to be studied are not yet clear, holistic, complex and meaningful. The results of this study indicate that the social media account Instagram @dispusipdajabar has utilized Instagram social media in an effort to promote the library at the West Java Regional Library and Archives Service by involving three dimensions of informing, persuading, and influencing. In utilizing Instagram social media in an effort to promote libraries at the West Java Regional Library and Archives Service, it is hoped that DISPUSIPDA JABAR needs to create more innovative content in order to increase publications in library promotion so that more people visit.
\end{abstract}

Keyword: Media social, Promote, Instagram

\section{PENDAHULUAN}

Perkembangan teknologi informasi menjadi hal yang paling sering ditemui dan rasakan dampaknya dalam berkehidupan bermasyarakat. Perkembangan teknologi komunikasi menghasilkan dampak perubahan dalam perilaku pencarian informasi di masyarakat. Saat ini secara langsung, masyarakat lebih condong dalam menggunakan teknologi sebagai sarana pencarian informasi. 
Dalam bidang komunikasi, penggunakan gadjet smartphone beberapa tahun terakhir menjadi berkembang. Jika dahulu kita rasakan keterbatasan dalam menggunakan handphone, saat ini handphone mulai berubah menjadi smartpone yang kerap kali dimanfaatkan oleh masyarakat dalam berkomunikasi ataupun menelusur informasi serta menjadi mendia hiburan dan healing tersendiri bagi penggunanya.

Smartphone saat ini bukan hanya menjadi media komunikasi verbal melainkan media komunikasi audio dan visual. Dengan menggunakan smarphone kita dapat memberikan, menerima pesan suara, gambar, serta video dalam melakukan komunikasi dua arah tanpa memandang jarak dan waktu, artinya komunikasi serta penelusuran informasi akan terjadi tanpa mengenal adanya batasan waktu.

Pendayagunaan gadjet smartphone dimasyarakat bukan hanya sekedar komunikasi saja, melainkan juga menjadi media bersosialisasi melalui platform media social semisal facebook, twitter, youtube, dan Instagram. Menurut Mudassir dalam Putut Suharso (2019), Negara Indonesia menjadi pemakai ke 4 terbesar dalam skala dunia yang memiliki 56 juta penduduk dalam menjalankan aktivitas media social.

Menurut Nasrullah dalam Wahyuningtyas (2015) menjelaskan bahwa media social merupakan medium di internet yang memungkinkan pengguna mempresentasikan dirinya maupun bekerjasama, berinteraksi, berkomunikasi, dan berbagi dengan pengguna lain serta membentuk ikantan social virtual. Namun, saat masa pandemic covid 19 ini, kegiatan social berupa berkumpul-kumpul serta berkerumun dengan banyak orang merupakan kegiatan yang dilarang dan mengancam keselamatan kesehatan masyarakat.

Hal tersebut yang memungkinkan adanya pelonjakan penggunaan media social dalam berkomunikasi, berinteraksi, dan berbagi dalam pergaulan. Hal ini juga dalam konteks pendayagunaan media social terjadi bukan hanya dari individu atau masyarakat saja, melainkan perusahaan - perusahaan dan lembaga institusi, termasuk perpustakaan menjadikan media social sebagai medium komunikasi dalam berinterkasi dengan para pemustakanya. 
Perpustakaan bisa kita katakan sebagai organisme yang berkembang, hal ini yang membuat seolah - olah menjadi lebih adaptif terhadap perubahan yang terjadi dimasyarakat. Dengan demikian perpustakaan beradaptasi dengan perkembangan zaman yang mana bertujuan untuk menhindari ketertinggalam dalam usaha perkembangan perpustakaan itu sendiri.

Pendayagunaan media social yang sering kita temui saat ini adalah platform media social Instagram. Platformm tersebut dapat dimanfaatkan perpustakaan dalam melakukan branding dan melaksanakan kegiatan promosi perpustakaan demi meningkatkan citra perpustakaan. Oosman (2014) mengatakan bahwa salah satu tujuan dari pemanfaatan media social Instagram adalah promosi.

Dalam pendayagunaan Instagram, perpustakaan sejatinya memiliki tujuan masing - masing tergantung dari kebijakan pengelola perpustakaan tersebut, namun tidak menutup kemungkinan bahwa sebagian besar penggunaan media social Instagram di tujukan untuk kegiatan promosi. Kegiatan promosi tersebut akan menghasilkan komunikasi dai arah yang mana menjadi umpan balik dalam memberikan pendapat dan pengalaman dari pemustaka.

Menurut Widuri (2015) promosi adalah bentuk komunikasi dalam penyampaian pesan yang mecakup beberapa aspek, yakni:

a. To inform atau mengkomunikasikan

Mengkomunikasikan berarti memberitahu akan hal yang tidak di ketahui sebelumnya. Pada konteks ini, perpustakaan menginformasikan apa yang dimiliki oleh perpustakaan kepada pemustaka

b. To influence atau mempengaruhi

Mempengaruhi berarti perpustakaan berupaya mempengaruhi pemustaka untuk dapat minimal berkunjung ke perpustakaan dengan memberikan informasi yang berkaitan dengan apa yang di butuhkan pemustaka

c. To persuade atau membujuk

Membujuk ini berarti perpustakaan berupaya merayu pemustaka untuk melakukan kegiatan di perpustakaan dan memanfaatkan fasilitas serta layanan yang ada di perpustakaan baik kegiatan literasi atau rekreasi. 
Perpustakaan umum sejatinya tersebar dan ada pada setiap daerah, salah satunya adalah Perpustakaan di Dinas Perpustakaan dan Kearsipan Daerah Provinsi Jawa Barat. Dinas Perpustakaan dan Kearsipan Daerah Provinsi Jawa Barat berlokasi di Jl. Kawaluyaan Indah III No.4, Jatisari, Kec. Buahbatu, Kota Bandung.

Setelah melakukan observasi mandiri, penulis menemukan beragam akun Instagram instansi perpustakaan, namun penulis membandingkan dengan Instagram perguruan tinggi Universitas Pendidikan Indonesia yang aktif serta interaktif. Kemudian, ditemukan lah akun Instagram yang interaktif dan aktif yakni pada Dinas Perpustakaan dan Kearsipan Daerah Jawa Barat. Dengan demikian berdasarkan pengalaman penulis tersebut, penulis ingin mengetahui pendayagunaan media sosial instagram dalam upaya promosi perpustakaan pada Dinas Perpustakaan dan Kearsipan Daerah Jawa Barat.

Tujuan dari penelitian ini adalah untuk mengetahui dampak dari pendayagunaan media sosial instagram dalam upaya promosi perpustakaan pada Dinas Perpustakaan dan Kearsipan Daerah Jawa Barat. Penulis berharap dalam penilitian ini, dapat menambah wawasan dan bermanfaat dalam bidang ilmu perpustakaan khusunya dalam kegiatan promosi perpustakaan. Selanjutnya, penelitian ini diharap mampu menjadi refleksi bagi Dinas Perpustakaan dan Kearsipan Daerah Provinsi Jawa Barat agar dapat berkembang lebih baik dan mampu mengoptimalkan penggunaan media social Instagram khusunya dalam promosi perpustakaan.

\section{METODE}

Jenis penelitian ini menggunakan metode kualitatif dengan pendekatan studi kasus, di mana permasalahan yang akan diteliti belum jelas, holistik, kompleks dan penuh makna. Penelitian kualitatif adalah penelitian untuk mengetahui fenomena tentang apa yang dialami oleh subjek penelitian misalnya perilaku, persepsi, motivasi, tindakan dan lain-lain dengan cara deskripsi dalam bentuk kata-kata dan bahasa (Moleong, 2012: 6). 
Subjek penelitian disebut dengan istilah informan, yaitu orang yang memberi informasi tentang data yang diinginkan peneliti berkaitan dengan penelitian yang sedang dilaksanakannya (Idrus, 2009: 91). Informan penelitian adalah bagian dari penelitian yang berperan sebagai subjek penelitian untuk menyampaikan informasi dan menjawab pertanyaan-pertanyaan penelitian. Untuk pemilihan informan peneliti menggunakan teknik purposive sampling. Purposive sampling adalah menentukan subyek penelitian sesuai dengan kebutuhan penelitian.

Jenis data yang digunakan data primer dan data sekunder. Data primer yaitu data yang diperoleh dari informan ketika observasi dan wawancara. Sedangkan data sekunder yaitu buku, jurnal, skripsi yang berhubungan dengan tindakan bibliocrime. Cara pengumpulan data dengan metode tiangulasi yaitu, observasi, wawancara, dan dokumentasi.

\section{HASIL DAN PEMBAHASAN}

\section{Deskripsi Informan}

Pemilihan informan berdasar pada pertimbangan yang dianggap tepat oleh peneliti untuk bisa mandapatkan informasi yang dirasa perlu. Dalam penelitian ini terdaat 13 informan valid yang terdiri dari mahasiswa Perpustakaan dan Sains Informasi UPI angkatan 2019 dan 2017 sebagai followers akun @dispusipdajabar sebagai berikut: 
Tabel 1. Daftar identitas informan

\begin{tabular}{|l|l|}
\hline Nama & Pendidikan \\
\hline 1 10:23:43 AM GMT+7 & Perpustakaan dan Sains Informasi 2019 \\
\hline Dwi Putri Mayang Arum & Perpustakaan dan Sain Informasi 2017 \\
\hline Afni Afifah & Perpustakaan dan Sain Informasi 2017 \\
\hline Mahda & Perpustakaan dan Sain Informasi 2017 \\
\hline cintami & Perpustakaan dan Sain Informasi 2017 \\
\hline Maitsa & Perpustakaan dan Sain Informasi 2017 \\
\hline Muhammad Ikhlasul Amali & Perpustakaan dan Sains Informasi 2019 \\
\hline Widia Nengsih & Perpustakaan dan Sains Informasi 2019 \\
\hline Aldi Permadi & Perpustakaan dan Sains Informasi 2019 \\
\hline Salma N & Perpustakaan dan Sains Informasi 2019 \\
\hline Cindy Fitria S & Perpustakaan dan Sains Informasi 2019 \\
\hline Melani & Perpustakaan dan Sains Informasi 2019 \\
\hline Ratu Tirmala RA & Perpustakaan dan Sains Informasi 2019 \\
\hline 1 1:03:29 PM GMT+7 & Perpustakaan dan Sains Informasi 2019 \\
\hline Syifa Safira Salsabila & Perpustakaan dan Sain Informasi 2017 \\
\hline RRQ.Hilmi & Perpustakaan dan Sain Informasi 2017 \\
\hline
\end{tabular}

Informan pada table tersebut telah bersedia melakukan wawancara secara online melalui media google form yang diajukan oleh peneliti. Kemdian, didapati hasil sebagai beikut:

1) Mengetahui akun Instagram @dispusipdajabar 93,8\%

2) Setuju bahwa akun @dispusipdajabar memberikan informasi mengenai hal anda tidak ketahui (Kegiatan perpustakaan, layanan, serta fasilitas) tentang Dispusipda Jabar 93,8\%

3) Setuju bahwa akun @ dispusipdajabar mempengaruhi anda untuk dapat berkunjung ke Dispusipda Jabar 87,5\%

4) Setuju bahwa akun @dispusipdajabar membujuk anda untuk dapat melakukan kegiatan di Dispusipda Jabar 75\% 


\section{Pendayagunaan Media Sosial Instagram Dalam Upaya Promosi} Perpustakaan Pada Dinas Perpustakaan dan Kearsipan Daerah Jawa Barat

Instagram adalah salah satu media social yang memiliki pertumbuhan pengguna yang paling signifikan di dunia. Instagram ini awalnya merupakan aplikasi untuk membagikan foto atau juga video yang dapat digunakan oleh penggunanya untuk berbagi kebahagiaan. Instagram juga memungkinkan penggunanya untuk memanfaatkan fasilitas seperti filter dan juga stiker yang tersedia di aplikasi Instagram.

Dengan aplikasi Instagram, para penggunanya dituntut untuk menjadi kreativ dan inovatif dalam memposting suatu konten karena komunikasi yang dilakukan di dalam aplikasi Instagram dapat berupa verval melalui video atau hanya berupa gambar. Hal tersebut dilakukan agar para pengikut dari suatu pemiliki akun Instagram dapat memahami hasil dari postingan yang di upload pada aplikasi Instagram.

Postingan yang ada pada suatu akun Instagram menjadi ranah sosialisasi dan ranah promosi media social. Hal ini yang kemudian menjadi peluang para pelaku bisnis dan lembaga profit dan nonprofit seperti perpustakaan memanfaatkan aplikasi Instagram. Salah satu perpustakaan yang memanfaatkan aplikasi media social Instagram ini adalah Dinas Perpustakaan Dan Kearsipan Jawa Barat (DISPUSIPDA JABAR) dengan nama kepemilikian akun @dispusipdajabar.

Selain memiliki tugas untuk melayani kebutuhan informasi masyarakat, DISPUSIPDA JABAR memiliki tanggung jawab untuk melakukan promosi perpustakaan dengan mamanfaatkan media social, salah satu yang dipilihnya adalah mendia social Instagram. Tentunya, hal ini menciptakan sebuah kegiatan dimana akun @dispusipdajabar dengan memberikan konten informative yang bersifat komunikatif, persuasive, dan influensive. Adapun hasil pendokumentasian dalam kegiatan promosi perpustakaan adalah sebagai berikut: 
1. Mengkomunikasikan (To Inform)

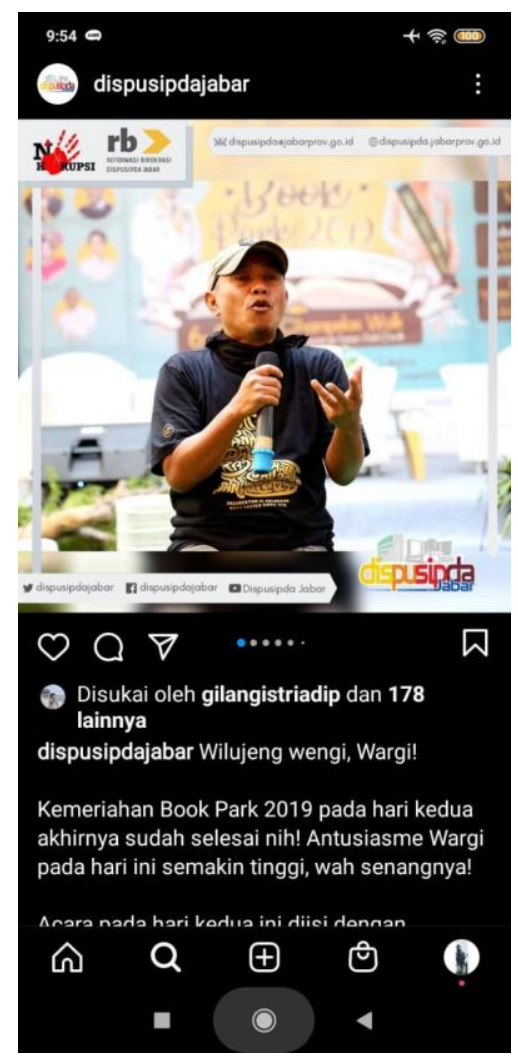

Gambar 1. Contoh postingan bersifat komunikative

(Sumber: @dsipusipdajabar)

Keigatan promosi perpustakaan yang dikelola oleh akun @dispusipdajabar adalah mengkomunikasikan event kegiatan. Berdasar pada gambar tersebut DISPUSIPDA JABAR menunjukan bahwa kegiatan apa yang dilakukan oleh DISPUSIPDA JABAR.

Dengan deimikian masyarakat mengetahui program layanan yang diberikan oleh DISPUSIPDA JABAR yaitu event kegiatan Book Park pada tahun 2019. Kegiatan ini merupakan program yang memiliki interaksi dengan pihak ketiga seperti 
masyarakat dan juga event organizer. DISPUSIPDA JABAR mendatangkan beberapa guest star yang cukup terkenal seperti Pidibaiq yang memang memiliki andil dalam kegiatan tulis menulis seperti novel Dia adalah ddilanku tahun 1991.

2. Mempengaruhi (To Influence)

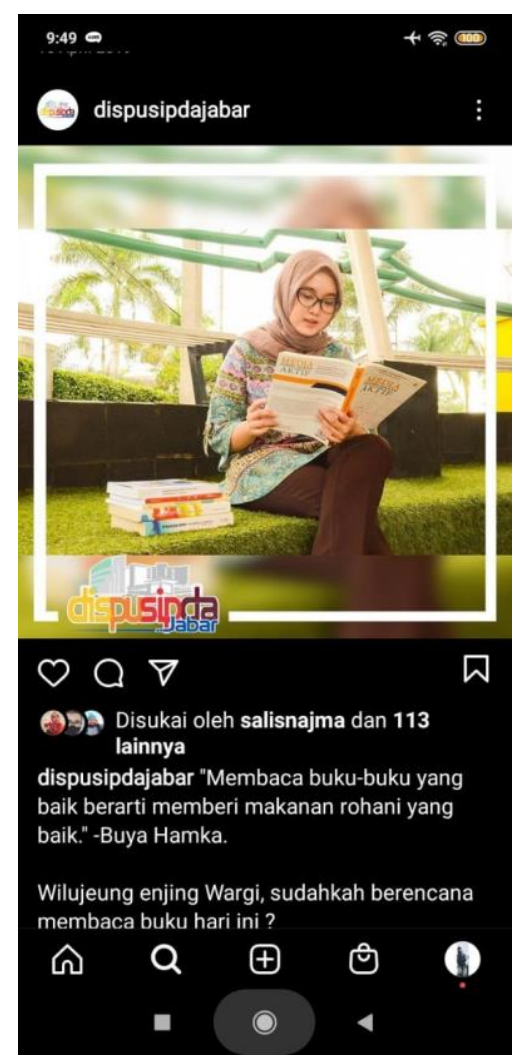

Gambar 2. Contoh postingan bersifat influensive

(Sumber: @dispusipdajabar)

Akun media social Instagram @dispusipdajabar secara tidak langsung mampu memberikan gambaran mengenai kondisi dan situasi dari Dinas Perpustakaan dan Kearsipan Jawa Barat melalui postingan sebiah postingan foto.

Pada postingan tersebut, kita dapat melihat pemustaka yang sedang ayik melakukan kegiatan membaca di taman DISPUSIPDA JABAR. Secara tidak langsung akun @dispusipdajabar mempromosikan fasilitas yang dimiliki dan 
memberikan pengaruh pada pandangan masyarakat betapa nyaman tempat yang dimiliki DISPUSIPDA JABAR yang mampu dimanfaatkan pemustaka.

3. Membujuk (To Persuade)

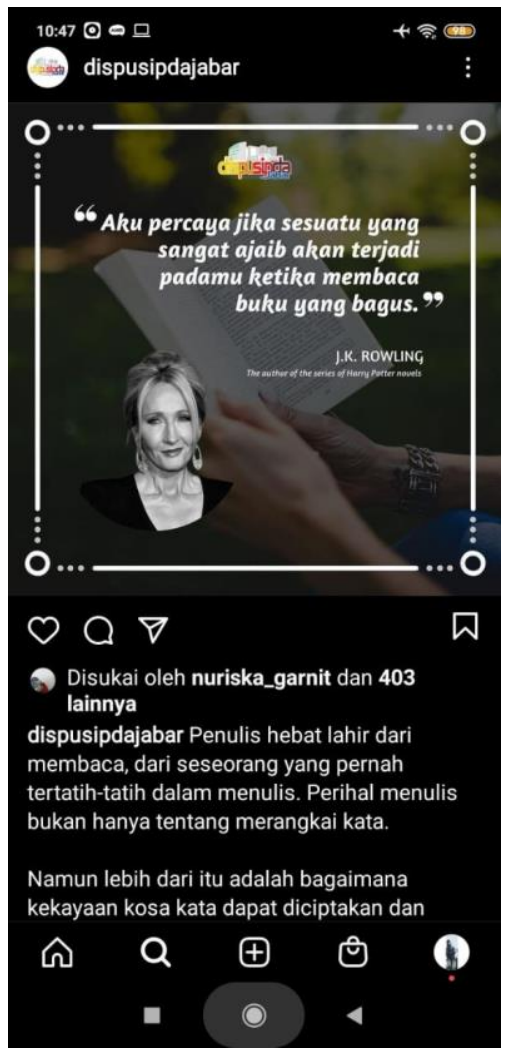

Gambar 3. Contoh postingan bersifat persuasive

(Sumber: @dispusipdajabar)

Pada akun Instagram @dispusipdajabar bukan hanya foto atau juga video yang tentang kegiatan yang di laksanakan di DISPUSIPDA JABAR, melainkan adanya juga quotes yang bersifat persuasive tentang motivasi serta ajakan untuk masyarakat supaya gemar membaca. 
Terlihat, secara tidak langsung, DiSPUSIPDA JABAR mempengaruhi masyarakat untuk meakukan kegiatan membaca di perpustakaan atau juga kegiatan lain yang di laksanakan oleh DISPUSIPDA JABAR.

Berdasar pada ketiga aspek mengkomunikasiakn (to inform), mempengaruhi (to influence), dan membujuk (to persuade), akun @dispusipda jabar elah melaksanakan kegiatan promosi perpustakaan dengan memanfaatkan media social Instagram dengan membagikan informasi (to fnform) tentang layanan pemustaa di Dinas Perpustakaan dan Kearsipan Daerah Jawa Barat. Akun @dispusipdajabar juga memberikan visual terkait kondisi dan keadaan perpustakaan melalui postingannya sebagai upaya mempengaruhi (to influence) dengan membuka pandangan masyarakan seberapa menyanangkan dan nyamannya tempat membaca di Dinas Perpustakaan dan Kearsipan Daerah Jawa Barat juga bujukan (to persuade) supaya masyarakat berkunjung ke DISPUSIPDA JABAR.

\section{PENUTUP}

\section{Simpulan}

Kesimpulan dari penelitian ini bahwa akun media social Instagram @ dispusipdajabar sudah melakukan pendayagunaan media sosial instagram dalam upaya promosi perpustakaan pada Dinas Perpustakaan dan Kearsipan Daerah Jawa Barat dengan melibatkan tiga dimensi yakni rpomosi yakni membagikan informasi (to inform) tentang layanan pemustaa di Dinas Perpustakaan dan Kearsipan Daerah Jawa Barat. Akun @dispusipdajabar juga memberikan visual terkait kondisi dan keadaan perpustakaan melalui postingannya sebagai upaya mempengaruhi (to influence) dengan membuka pandangan masyarakan seberapa menyanangkan dan nyamannya tempat membaca di Dinas Perpustakaan dan Kearsipan Daerah Jawa Barat juga bujukan (to persuade) supaya masyarakat berkunjung ke DISPUSIPDA JABAR.

\section{Saran}

Dalam pendayagunaan media sosial instagram dalam upaya promosi perpustakaan pada Dinas Perpustakaan dan Kearsipan Daerah Jawa Barat perlu 
membuat konten yang lebih inovatif demi meningkatkan publikasi dalam promosi perpustakaan agar semakin banyak masyarakat yang berkunjung ke DISPUSIPDA JABAR dan menjadi pemustaka yang loyal dan potensial.

\section{DAFTAR PUSTAKA}

Miyata, N. S. (2019). Efektivitas Penggunaan Instagram Sebagai Media Promosi Perpustakaan Universitas Kristen Petra. AGORA.

Prabowo, A. (2019). Mediatisasi Perpustakaan Perguruan Tinggi Di Yogyakarta Pada Instagram Dalam Promosi Kepada Masyarakat. Nusantara Journal of Information and Library Studies, 171-187.

Suharso, P. (2019). Promosi Perpustakaan Melalui Instagram: Studi di Perpustakaan Universitas Airlangga. Publication Library And Information Science, 66-74.

Tatarina, W. A. (2017). Dampak Media Sosial Instagram @ Jaklib_Cikini Sebagai Media Promosi Perpustakaan Umum Daerah Provinsi DKI Jakarta Cikini. EJournal UNDIP: Jurnal Ilmu Perpustakaan.

Zuhri, M. A. (2019). Pemanfaatan Media Sosial Instagram Sebagai Media Promosi Library Based Community (Studi Kasus Komunitas Perpustakaan Jalanan Solo @ Koperjas. E-Journal UNDIP: Jurnal Ilmu Perpustakaan. 